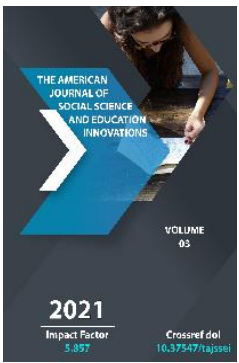

\title{
Automated System Of Assessment Of Occupations In Higher Educational Institutions
}

\author{
Sharipova Alsu Rafikovna \\ Doctoral Student, Tashkent State Transport University, Tashkent, Uzbekistan
}

Journal Website:

http://theamericanjour

nals.com/index.php/taj

ssei

Copyright: Original content from this work may be used under the terms of the creative commons attributes 4.0 licence.

\section{ABSTRACT}

This article examines the main criteria for assessing university studies. The problems faced today are analyzed. An automated system for assessing university studies has been proposed, which will allow the output of the necessary statistical data to improve the quality of education.

\section{KEYWORDS}

Assessment of classes, automated system of assessment of classes, questionnaire, higher educational institution, quality of education, the concept of development.

\section{INTRODUCTION}

Human capital, intellectual potential and the knowledge economy in modern society are of great importance and influence on the development and well-being of any country. The issue of quality is becoming the most relevant in any area of human activity. The system of higher education is no exception, since it, in the context of the rapid development and dissemination of innovative technologies, scientific and technological progress is a preparatory link for highly qualified specialists for the economy, production and management [1]. And in order to improve the quality of the higher education system in the Republic of Uzbekistan, the Concept for the Development of Higher Education in the Republic of Uzbekistan until 2030 (hereinafter the Concept) was adopted. According to this concept, it was decided to gradually transfer the educational process of higher educational institutions to a creditmodular system; introduce advanced standards of higher education, establish a system of training highly qualified personnel [2]. All ongoing work on the modernization of the higher education system of the Republic of Uzbekistan in accordance with the Concept is aimed at improving the quality of education and raising the content of higher education to a qualitatively new level. And in order to improve the quality of the education system, 
first of all, it is necessary to improve the quality of classes and educational skills of teachers in higher educational institutions. And in order to improve the quality of classes and the teaching skills of teachers, first, it is necessary to analyze the classes and evaluate them.

\section{THE MAIN PART}

A significant number of scientific publications are devoted to the problems of the development and improvement of the quality of education in various aspects of its study, the study of the general principles of monitoring the quality of educational activities and its management, the study of the experience of using international programs for assessing the quality of education, which include A. Bermusa, A. Bordovsky, Itin, L. Nesterova, S. Redko, T. Trapitsyna, G. Walford, F. Kaiser, I. Kovalenko. There are also many methods for assessing the quality of classes, developed by M.N. Berulava, T.I. Ilyina, I.G. Shtokman, et al [3].

The complexity and versatility of the tasks facing higher education require the creation of an objective, consistent and effective assessment and control of the quality of classes, which would not only track the results of the educational activities of the university but also actively influence the quality of its functioning. In this article, we propose to introduce an automated system for assessing the quality of university studies and, in general, an assessment of the organizational and methodological work of a teacher in the educational process, created on the basis of a questionnaire on learning skills (ISQ).

In terms of their structure, classes in higher educational institutions may differ from one another. It all depends on the content and nature of the material presented, but there is a general structural framework applicable to any occupation.
As a rule, university studies are assessed according to the following criteria:

- Assessment of the teacher himself

- Assessment of the quality of classes by inspectors (head of the department or commission);

- Assessment of the quality of classes by consumers (students);

- Assessment over several years [4]

According to the literature, for activity assessment to be effective, it must be timely, specific, reliable and contribute to realistic behaviour change $[5,6]$. Often the ratings do not meet these requirements. Firstly, in most cases, classes are not assessed by the teacher himself, since today there are no specific questionnaires for assessing classes by the teacher himself. Secondly, when assessing the quality of classes by consumers (student reviews) are carried out mainly at the end of a semester or course, and the answers collected at the end of a semester or course may not be timely. In most cases, faculty cannot use testimonials until the next semester or year. Thirdly, the assessment of the quality of classes by the inspectors is generally not accompanied by expert advice. Combining this intermediate feedback with (expert) consultation has proven to be even more effective $[7,8]$. Fourth, there is no collection and analysis of data (estimates) for a certain period of time to display the assessment of classes over several years. Fifth, the standard course assessment questionnaires are not suitable for intermediate use. Research has shown that intermediate (often mid-term) feedback is more effective than feedback at the end of the academic year in improving student teaching grades over time [9,10]. Both common questionnaires are designed to assess completed courses, and problems such as the limited number of questions often make it difficult to reliably measure the multidimensionality of the instructor's learning skills. 
Our proposed scheme for assessing university studies, in our opinion, works well in assessing any form of education since it is based on the basic principles.

An automated system for assessing the quality of university studies, created on the basis of ISQ, is carried out immediately after one lesson, which will allow the teacher to evaluate the lesson himself, as well as the consumer (students). All data is stored within the system, and, if necessary, the teacher can display the analysis of the lesson's assessment in the form of a diagram. Inspectors (head of the department, commission) also assess the lesson within this system. Since in this system, there is already a questionnaire for assessing the teacher by the assessor. All marks for the lessons are summed up and, if necessary, through the teacher's personal account, you can display the results of the assessments of the lessons during the selected period. Such statistics will allow, with full automation of the assessment of the classes of a higher educational institution, to derive the rating of teachers.

The automated system for assessing the quality of university studies contains questions on seven dimensions of academic skills:

- Structure: the degree of systematic and orderly work with the subject.

- Legend: The degree to which the instructor explains a subject, especially more complex topics.

- Incentives: the degree to which the teacher interests students in the subject

- Validation: The degree to which the instructor emphasizes the benefits and relevance of the subject for educational purposes or a future profession.

- Instruction: the degree to which the instructor gives instruction on how to learn a subject
- Comprehension: the degree to which the instructor creates opportunities for questions and comments on a subject.

- Activation: The degree to which the instructor encourages students to actively think about the subject [10].

An automated system for assessing the quality of university studies created on the basis of ISQ is considered a reliable and valid tool that can be used to provide faculty members with specific, timely and relevant feedback on various aspects of their teaching. This will allow them to evaluate, improve and reevaluate their learning skills during their studies. The system is also useful for centres of excellence for teachers and consultants as a source of intermediate feedback.

\section{REFERENCES}

1. Tyurikov A.G. (2019). New practices of sociological diagnostics of the demand and quality of educational services of universities: methodological and methodological problems. Innovations in education. No. 2. pp.21-33.

2. The concept for the development of higher education in the Republic of Uzbekistan until 2030. (2020). National Database of Legislation, 09.10.2019, No. 06/19/5847/3887; April 30, No. 06/20/5987/0521.

3. Sergeeva S.Yu. (2019). Modern approaches and methods for assessing the quality of education. Young scientist. No. 37 (275). pp.162165.

4. Mustafina G.A., Bineeva F.N. (2007). Monitoring the assessment of the quality of a university lecture, Volzhsky.pp.1-2

5. Hattie J., Timperly H. (2007). The power of feedback. Review of educational research.77 (1): pp. 81-112.

6. McLaughlin M.W., Pfeifer R.S. (1988). Teacher Assessment: Improvement, 
Accountability and Effective Learning: ERIC;.

7. Penny AR, Coe R. (2004). Effectiveness of feedback consultation on student assessments: a meta-analysis. Review of educational research. 74 (2). pp. 215-53.

8. Knol M.H., In't Veld R., Vorst H.C.M., van Driel J.H., Mellenbergh G.J. (2013). Experimental effects of student assessments combined with collaborative counseling on the academic skills of college teachers. Research in Higher Education. 54(8). pp. 825-50.

9. Cohen P.A. (1980). Effectiveness of student rating feedback for improving college learning: a meta-analysis of outcomes. Research in Higher Education. 13 (4). pp. 321-41.

10. Knol, M. H., Dolan, C. V., Mellenbergh, G. J., \& van der Maas, H. L. (2016). Measuring the quality of university lectures: Development and validation of the Instructional Skills Questionnaire (ISQ). PloS one, 11(2), e0149163. 